\title{
Diagnostico da fragilidade ambiental na Bacia do Submédio Tocantins: UHE Tucuruí
}

As geotecnologias cumprem um papel importante, relacionados à fragilidade do ambiente, pois são capazes de elaborar produtos capazes de identificar pontos de destaque e são altamente eficientes para a gestão do território e promoção da qualidade da paisagem. Este trabalho apresenta um modelo para determinar a fragilidade ambiental em bacias hidrográficas. O estudo foi realizado na Bacia do Submédio Tocantins, localizada na bacia hidrográfica do Tocantins-Araguaia. Fatores que influenciam a ocorrência de processos de vulnerabilidade ambiental foram integrados por algoritmos em um SIG para construção de classes de fragilidade. A análise multicriterial considerou o modelo numérico de terreno, dados oficiais sobre variáveis ambientais e imagem orbital de alta resolução. Através de informações secundárias sobre pedologia, intensidade das chuvas e declividade do terreno, gerou-se o Mapa de Fragilidade Potencial (MFP). Em seguida, foram sobrepostas ao MFP as informações sobre uso e cobertura da terra gerando, assim, o Mapa de Fragilidade Emergente (MFE). Os resultados mostram que mais de $50 \%$ da área da bacia possui fragilidade potencial considerada baixa ou muito baixa, enquanto mais de $30 \%$ da área da bacia possui fragilidade emergente. Os modelos geraram informações importantes para o planejamento territorial, possibilitando um zoneamento acessível e de fácil atualização para as prefeituras municipais e organizações da sociedade civil, inclusive para o monitoramento das áreas de alta fragilidade ambiental.

Palavras-chave: Fragilidade Potencial; Fragilidade Emergente; Geoprocessamento; Planejamento territorial.

\section{Diagnosis of the environmental fragility in the Tocantins Submedia Medium Basin: Tucuruí HPP}

Geotechnologies play an important role, related to the fragility of the environment, as they are capable of elaborating products capable of identifying points of prominence and are highly efficient for the management of the territory and the promotion of landscape quality. This paper presents a model for determining environmental fragility in watersheds. The study was conducted in the Tocantins Submediate Basin, located in the Tocantins-Araguaia watershed. Factors that influence the occurrence of environmental vulnerability processes were integrated by algorithms in a GIS for the construction of frailty classes. The multicriteria analysis considered the numerical terrain model, official data on environmental variables and high resolution orbital imaging. Through secondary information on pedology, rainfall intensity and terrain slope, the Potential Fragility Map (MFP) was generated. Then, the land use and land cover information was superimposed on the MFP, thus generating the Emerging Fragility Map (MFE). The results show that more than $50 \%$ of the basin area has potential fragility considered low or very low, while more than $30 \%$ of the basin area has emergent fragility. The models generated important information for territorial planning, enabling an accessible and easily updated zoning for municipal governments and civil society organizations, including for monitoring areas of high environmental fragility.

Keywords: Potential Fragility; Emerging Fragility; Geoprocessing; Territorial planning.

Topic: Engenharia Ambiental

Reviewed anonymously in the process of blind peer.
Received: $14 / 01 / 2019$

Approved: 15/02/2019
Leoni de Souza Belato (iD)

Universidade Federal do Pará, Brasil

http://lattes.cnpq.br/7063630868527586

http://orcid.org/0000-0002-9230-2246

leonibelato@gmail.com

Sérgio Luis Cardoso Serrão

Instituto Tecnológico Vale, Brasil

http://lattes.cnpq.br/7255962059886608

http://orcid.org/0000-0002-0803-2627

seuserrao@gmail.com

\section{Rafael Pompeu Dias}

Instituto Tecnológico Vale, Brasil

http://lattes.cnpq.br/5061243034932992

rafaelp.dias@yahoo.com.br

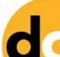

DOI: 10.6008/CBPC2237-9290.2019.001.0004

\section{Referencing this:}

BELATO, L. S.; SERRÃO, S. L. C.; DIAS, R. P.. Diagnostico da fragilidade ambiental na Bacia do Submédio Tocantins: UHE Tucuruí. Natural Resources, v.9, n.1, p.28-37, 2019. DOI:

http://doi.org/10.6008/CBPC2237-9290.2019.001.0004 


\section{INTRODUÇÃO}

O homem se relaciona com a natureza a partir das diferentes formas de ocupação e utilização do ambiente natural, e com isso, ocorrem intervenções antrópicas nos sistemas ambientais, resultando em menor ou maior fragilidade em função de suas características biogenéticas (ROSS, 1994). Qualquer alteração nos componentes da natureza (relevo, solo, vegetação, clima e recursos hídricos) acarretam comprometimentos na funcionalidade do sistema, ocasionando instabilidades no equilíbrio dinâmico (SPÖRL, 2004). Neste sentido, o uso sustentável dos recursos naturais, especialmente do solo, tem sido um tema de relevância significativa nas mesas de debate acadêmicos, devido principalmente a pressão que o antropocentrismo acarreta no meio ambiente (ARAUJO, 2007).

As premissas do planejamento ambiental definem-se como um conjunto de complexos elementos em interações ordenadas, e a partir do conceito de dinâmica dos ambientes, é possível determinar suas potencialidades e fragilidades para o uso humano (ROSS, 1994). Os estudos relativos à fragilidade dos ambientes são de extrema importância ao Planejamento Ambiental, onde a identificação dos ambientes naturais e suas fragilidades potenciais e emergentes proporcionam uma melhor definição das diretrizes e ações a serem implementadas no espaço físico-territorial, servindo de base para o zoneamento e fornecendo subsídios à gestão do território (SPÖRL, 2004).

As geotecnologias cumprem um papel importante relacionados a fragilidade do ambiente, pois são capazes de elaborar produtos cartográficos, identificando os pontos de destaque e são altamente eficientes para a gestão do território e promoção da qualidade da paisagem, por isso nos últimos anos a técnica tem sido largamente difundida no Brasil (RODRIGUES et al., 2001).

Os Sistemas de Informação Geográfica (SIG) podem ser utilizados para facilitar a realização de operações complexas, pois permitem integrar grandes volumes de dados cartográficos com naturezas e escalas diferentes como: vetores em shapefile, imagens de sensores remotos, imagens fotogramétricas, dados topográficos, dados primários e secundários, etc..

Os sistemas ambientais respondem de diferentes formas às intervenções antrópicas nos componentes da paisagem (relevo, solo, clima, recursos hídricos e cobertura vegetal). Mapear a fragilidade ambiental permite abrir um leque de opções e detectar áreas frágeis, suscetíveis ao risco e que merecem maior atenção dos gestores, pois, a utilização de forma incorreta pode resultar grandes comprometimentos de todo o sistema ambiental.

Com o auxílio de geotecnologias, de SIG e de conceitos de sistemas ambientais, gera-se o mapa de fragilidade ambiental, que constitui uma importante ferramenta que pode ser utilizada pelos órgãos públicos competentes para o planejamento territorial, em escala regional ou local, pode ser utilizado também por pequenos proprietários e produtores rurais, na gerencia de suas terras pois possibilita a avaliação das características ambientais de forma integrada (KAWAKUBO et al., 2005).

Desta forma, o trabalho tem como objetivo mapear a fragilidade ambiental da Bacia Hidrográfica do Submédio Tocantins, na perspectiva de uma unidade integradora, constituída de elementos naturais 
(declividade, vegetação, solo e clima) e sociais (usa da terra), na intenção de identificar o menor e o maior grau de fragilidade dos ambientes, indicada pelo mapa de fragilidade potencial e emergente.

A escolha da área se deu devido a presença do Projeto Grande Carajás na região, a partir dos anos de 1970, e dentro do plano estava previsto a construção de uma Usina hidrelétrica, e com isso houve a necessidade modificar os aspectos físicos da região. Com a existência das eclusas, que foram construídas logo após a UHE Tucuruí, o rio Tocantins, possibilita a navegação fluvial, com isso a área possui extrema necessidade de um planejamento ambiental adequado, pois a identificação proporciona uma melhor definição das ações a serem implantadas em um espaço físico-territorial.

\section{MATERIAIS E MÉTODOS}

A bacia do Submédio Tocantins, ilustrada na figura 1, na qual está instalada a Usina Hidrelétrica de Tucuruí - UHE, abrange os municípios de Goianésia do Pará (4,30\%), Breu Branco (2,67\%), Tucuruí (7,68\%), Novo Repartimento (31,40\%), Jacundá $(7,77 \%)$, Nova Ipixuna $(7,92 \%)$, Itupiranga $(38,27 \%)$, incluindo parte da Área Indígena Parakanã, está localizada na Região Hidrográfica Tocantins-Araguaia, Submédio Rio Tocantins, margem direita do rio, Sudeste do Estado do Pará, (ALVES, 2005). A área de influência da usina de Tucuruí é uma Área de Proteção Ambiental (APA), Lei n 6451/02, da Secretaria de Ciência e Tecnologia e Meio Ambiente do Estado do Pará (SECTAM/PA).

A região apresenta uma estação chuvosa, de dezembro a maio atingindo de 500 a $600 \mathrm{~mm}$ de chuva, e uma estação seca, de junho a novembro, com período de estiagem pronunciado de agosto a setembro (LIMA, 2008). A bacia do Submédio Tocantins tem uma área de $20.450,80 \mathrm{~km}^{2}$ e deságua na baía do Marajó. O rio Tocantins apresenta suas maiores vazões entre dezembro e maio e as menores nos meses de agosto a outubro, fato fortemente influenciado pelo regime pluvial da região (ALVES, 2005).

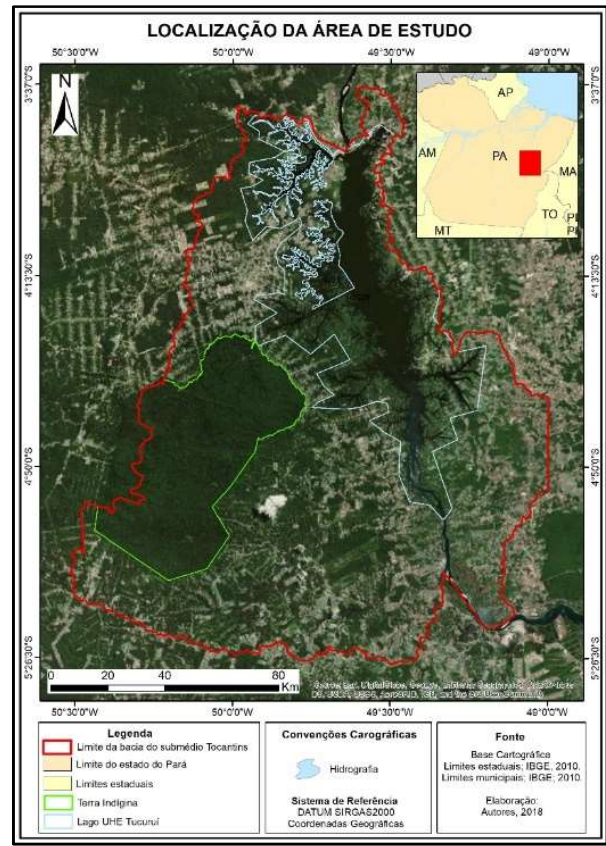

Figura 1: Localização da Bacia do Submédio Tocantins (PA). 
A UHE de Tucuruí é a maior da Região Norte do Brasil, pertence às Centrais Elétricas do Norte do Brasil (Eletronorte), possui uma área de cerca de $2.430 \mathrm{~km}^{2}$ (ELETROBRÁS, 1990) e é a maior usina hidrelétrica em funcionamento no país com 8.370.000KW de potência (ANEEL, 2008). Tucuruí Localiza-se no estado do Pará, entre as coordenadas $3^{\circ} 45^{\prime}$ e $5^{\circ} 15^{\prime}$ latitude Sul e $49^{\circ} 12^{\prime}$ e $50^{\circ} 00^{\prime}$ longitude Oeste (Espíndola et al., 2000). O lago formado com a inundação da área possui aproximadamente 72 metros de profundidade, comprimento de $170 \mathrm{~km}$ no sentido norte-sul e cerca de 1.600 ilhas (SANCHES et al., 2005).

Para a confecção dos mapas foi utilizado o software Arcgis 10.5. Esse programa apresenta uma plataforma de SIG (Sistema de Informações Geográficas), possibilitando a manipulação de feições espaciais georreferenciadas associadas a um banco de dados com as informações analíticas, além de permitir o cruzamento entre os mapas produzidos.

Foram utilizados arquivos vetoriais em formato shapefile e, os atributos utilizados como critério para definição das classes de fragilidade ambiental foram: vegetação, pedologia, do ano de 2010, obtidos junto ao site do IBGE (Instituto Brasileiro de Geografia e Estatística), precipitação média trimestral (mm/ano), declividade do terreno (\%), e os arquivos do mapeamento do uso do solo do projeto TERRACLASS, do ano de 2014, Orbita 223, Ponto 064, obtidos junto ao site do INPE (Instituto Nacional de Pesquisas Espaciais), os dados foram cruzados e transformados em arquivos de formato de saída RASTER, sua finalização se deu com a inclusão dos elementos cartográficos obrigatórios (fonte, legenda, orientação e escala).

Os mapas de fragilidade potencial e emergente da bacia do Submédio Tocantins foram elaborados a partir da integração dos índices de fragilidade de cada atributo dos meios físico, biótico e das formas de uso do solo, gerando, em um primeiro momento, os mapas de pedologia, vegetação, precipitação e declividade, voltados a elaboração do mapa de fragilidade potencial. Em um segundo momento, o mapa de uso do solo foi sobreposto ao mapa de fragilidade potencial, resultando em um mapa de fragilidade Emergente (figura 2). Os valores do grau de fragilidade de cada atributo foram adaptados da metodologia empregada por Valle et al. (2016) e Grigio (2003). Utilizou-se na determinação do grau de vulnerabilidade de cada atributo a relação de predomínio entre os processos erosivos e pedogenéticos.

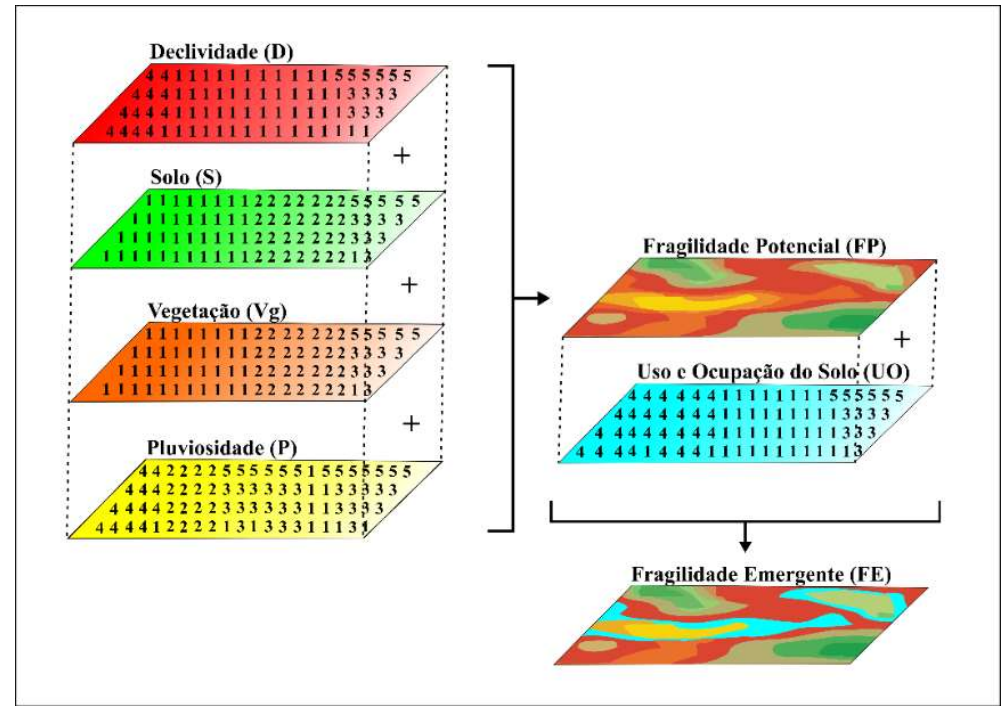

Figura 2: Roteiro para elaboração dos mapas de fragilidade potencial e emergente. Fonte: Costa et al. (2006). 
Em cada classe, o grau de vulnerabilidade foi distribuído em uma escala de 1 a 5, com intervalos de 1. Com predominância da pedogênese, fragilidade muito baixa, atribuiu-se o valor de 1 . Com o aumento da influência dos processos erosivos, o grau de fragilidade aumenta até atingir o valor máximo, sendo 5, representando ambientes de fragilidade muito alta (VALLE et al., 2016). A tabela 1 apresenta o índice de fragilidade de cada atributo ambiental. Com isso, foram formadas cinco classes de fragilidade com intervalos iguais. A tabela 2 representa as classes de fragilidade potencial e emergente, formadas pelos cruzamentos dos diversos atributos analisados.

Tabela 1: Índice de fragilidade potencial e emergente dos elementos da paisagem.

\begin{tabular}{|c|c|}
\hline Atributos Ambientais & Índice de fragilidade potencial e emergente \\
\hline \multicolumn{2}{|c|}{ Vegetação } \\
\hline Floresta Ombrófila Aberta Submontana & 2 \\
\hline Floresta Ombrófila Aberta Submontana com palmeiras & 2 \\
\hline Floresta Ombrófila Densa Aluvial & 1 \\
\hline Floresta Ombrófila Densa das Terras Baixas & 1 \\
\hline Floresta Ombrófila Densa Submontana & 1 \\
\hline Floresta Ombrófila Densa Submontana com dossel emergente & 1 \\
\hline Pecuária (pastagens) & 4 \\
\hline Vegetação Secundária com/sem palmeiras & 3 \\
\hline Corpo d'água continental & 2 \\
\hline \multicolumn{2}{|c|}{ Pedologia } \\
\hline Corpos d’água continental & 2 \\
\hline ESKg - Espodossolo Ferrihumilúvico Hidromórfico & 4 \\
\hline FXd - Plintossolo Háplico Distrófico & 5 \\
\hline GXbd - Gleissolo Háplico Tb Distrófico & 5 \\
\hline LAd - Latossolo Amarelo Distrófico & 1 \\
\hline PVAd - Argissolo Vermelho-Amarelo Distrófico & 1 \\
\hline RLd - Neossolo Litólico Distrófico & 5 \\
\hline \multicolumn{2}{|c|}{ Declividade } \\
\hline Plano & 1 \\
\hline Suave Ondulado & 2 \\
\hline Ondulado & 3 \\
\hline Forte Ondulado & 4 \\
\hline Montanhoso e escarpado & 5 \\
\hline \multicolumn{2}{|c|}{ Pluviosidade } \\
\hline Muito Fraco & 4 \\
\hline Fraco & 4 \\
\hline Médio & 4 \\
\hline Forte & 4 \\
\hline Muito Forte & 4 \\
\hline \multicolumn{2}{|c|}{ Uso e ocupação } \\
\hline Área Não Observada & 5 \\
\hline Área Urbana & 3 \\
\hline Desflorestamento & 5 \\
\hline Floresta & 1 \\
\hline Hidrografia & 2 \\
\hline Mineração & 5 \\
\hline Mosaico de Ocupações & 3 \\
\hline Não Floresta & 4 \\
\hline Outros & 3 \\
\hline Pasto com Solo Exposto & 4 \\
\hline Pasto Limpo & 4 \\
\hline Pasto Sujo & 4 \\
\hline Reflorestamento & 2 \\
\hline Regeneração Com Pasto & 4 \\
\hline Vegetação Secundária & 4 \\
\hline
\end{tabular}

Fonte: Costa et al. (2006, 2018). 
Tabela 2: Classes de fragilidade potencial e emergente.

\begin{tabular}{|c|c|}
\hline Classes & Médias \\
\hline Muito Baixa & $0-0,57$ \\
\hline Baixa & $0,57-1,95$ \\
\hline Média & $1,95-3,55$ \\
\hline Alta & $3,55-4,23$ \\
\hline Muito Alta & $4,23-5$ \\
\hline
\end{tabular}

\section{RESULTADOS E DISCUSSÃO}

A localização e a topografia na região da Bacia do Submédio Tocantins favorecem a ocorrência de fortes chuvas em períodos bem definidos: o chuvoso, intensificadas nos meses de outubro a abril com mais de $90 \%$ da precipitação, com a existência de alguns dias secos entre janeiro e fevereiro, formando o chamado veranico; e o seco, de maio a setembro, com baixa umidade relativa do ar (ANA, 2002). Isso deu suporte para a atribuição de um valor constante para a fragilidade ambiental no que se refere ao fator pluviosidade - peso 4, vulnerabilidade Forte (ROSS, 2012). Nesse sentido, o diagnóstico da fragilidade ambiental (potencial e emergente) apresentaram variabilidade espacial em diferentes níveis de fragilidade.

De acordo com o mapa de declividade do terreno destaca-se o alto grau de vulnerabilidade ambiental associado às áreas com passagens rochosas e baixo grau de vulnerabilidade a áreas com declividades da linha d'água superiores a $50 \mathrm{~cm} / \mathrm{km}$. No entanto, as condições limitantes à ocupação humana favorecem a manutenção da cobertura florestal nessas áreas, o que minimiza o risco à erosão relacionada aos fatores naturais na bacia em estudo (Fragilidade Potencial).

Em relação a pedologia, os dados de levantamento e a classificação de solos são apresentados no Sistema Brasileiro de Classificação Pedológica (EMBRAPA, 1999). Os solos de maior evidência na região são Latossolos Vermelho-Amarelo e Vermelho com texturas variáveis de média a argilosa, associados comumente a Solos Concrecionais, Neossolos Quartzarênicos, Argissolos e eventualmente, a outros solos (FGV, 1998). Solos considerados jovens e pouco desenvolvidos apresentam grau máximo de vulnerabilidade ambiental como, por exemplo, os Gleissolos e os Neossolos (LEME, 2007). Essa alta vulnerabilidade pode ser explicada pelo baixo grau de desenvolvimento de processos pedogenéticos identificados pela distribuição dos horizontes/camadas.

Em áreas com passagens rochosas e áreas de baixada, a hierarquização das classes pedológicas - de acordo com os pesos atribuídos por Crepani et al. (2001) - apontou vulnerabilidade muito alta. Nesse caso, associada à ocorrência de Gleissolos, ocupando uma área de $(0,07 \%)$ em planícies fluviais, com drenagem deficiente e baixa velocidade de infiltração da água, favorecendo o escoamento superficial. Os Neossolos, que correspondem às áreas de maior declividade abrangendo uma pequena parcela da área $(0,02 \%)$ por sua vez, propiciam a remoção de material do solo e inibem processos pedogenéticos.

Os Latossolos, com área de (10,18\%), ocorrem quase sempre nos chapadões ou superfícies de erosão estabilizadas mais antigas, assim como, também, nas pediplanícies e fluvioplanícies interiores. Os argissolos, cobrindo grandes extensões $(76,92 \%)$ nas áreas dissecadas da região, frequentemente ocorrem associados a outros solos, em manchas de pouca expressão (ANEEL, 1998). 
O uso da terra influencia diretamente a vulnerabilidade do terreno (JAIN et al., 2002). A grande disponibilidade de recursos naturais na região, de certa forma, favoreceu a visão de inesgotabilidade, refletindo nas práticas de uso e ocupação do solo. A forma desordenada de manejo e gestão de recursos constituem um traço representativo da cultura regional, o que é insustentável a médio e longo prazo (ANEEL, 1998). Dentre os diversos usos do solo da região, destacam-se os projetos de irrigação, mineração, garimpos, os aproveitamentos hidrelétricos, dentre outros. O processo de urbanização também é crescente, principalmente devido aos projetos de assentamentos do Incra, que disputam o espaço destinado às áreas prioritárias para conservação da biodiversidade.

Na área da bacia do Submédio Tocantins, encontrasse Corredores Ecológicos (Terra Indígena e Unidade de Conservação situada nos limites do lago da UHE - Tucuruí), que se constituem como instrumento importante de planejamento no sentido de potencializar a cooperação entre as diversas esferas de governo e segmentos da sociedade civil com objetivo de buscar a conciliação entre a conservação da biodiversidade e o desenvolvimento socioeconômico.

A integração dos mapas de fragilidade por unidades de mapeamento, complementada por consultas de especialistas para as pontuações aferidas, possibilitaram a construção da matriz de fragilidade e a interpretação dos resultados obtidos. Através da sobreposição dos subprodutos foi possível verificar casualidade no fato de algumas unidades serem mais sujeitas à alta vulnerabilidade do que outras, mesmo sob condições ambientais muito semelhantes (VALLE et al., 2016). A Bacia do Submédio Tocantins, através da integração dos atributos do terreno e uso da terra, em relação a seus efeitos sobre a estabilidade dos ambientes, foi representada pela classe de fragilidade alta (potencial e emergente) (figuras 2 e 3) (VALLE et al., 2016).

Analisando-se a distribuição relativa da área ocupada pelos diferentes graus de fragilidade foi possível constatar que, de uma forma geral, a bacia hidrográfica do Submédio Tocantins apresenta fragilidade potencial (figura 2) baixa e muito baixa, que ocupam $58,51 \%$ e a fragilidade potencial média ocupa uma área de $22,19 \%$, restando para fragilidade alta e muito alto uma área de $3.913,58 \mathrm{~km}^{2}$, aproximadamente $20 \%$ da bacia.

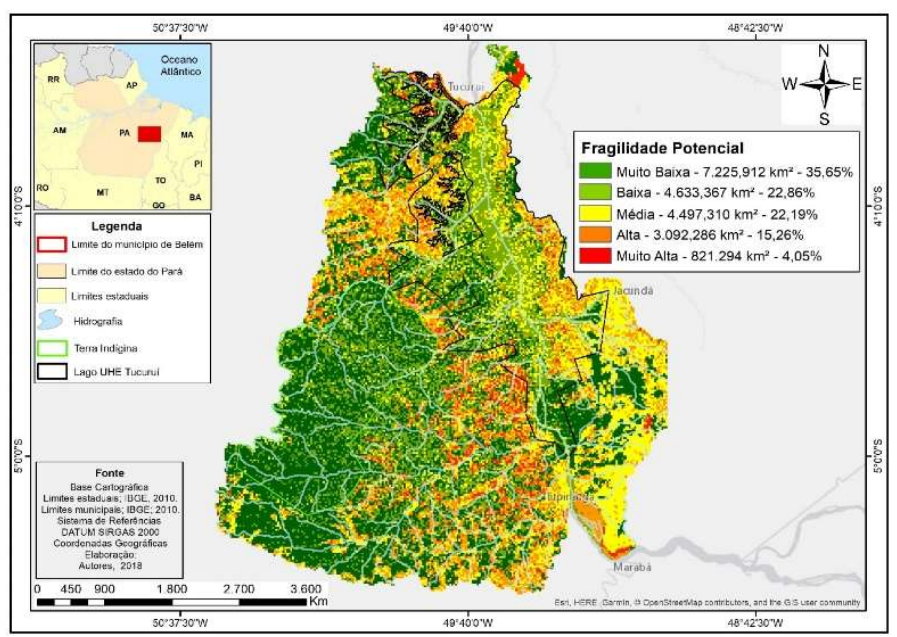

Figura 3: Mapas de Fragilidade Ambiental Potencial na bacia hidrográfica. 
Integrando o Mapa de Fragilidade Potencial ao mapa de uso e ocupação da terra, tem-se o Mapa de Fragilidade Emergente (figura 4), onde é constatada a predominância da classe fragilidade alta, ocupando 24,66\% da bacia, sendo a classe de fragilidade muito alta correspondente a 4,05\% da área da bacia. Esse resultado demonstra a influência das atividades desempenhadas pelo Homem na estabilidade do ambiente, sendo importante salientar a contribuição da cobertura florestal presente na área, que proporciona proteção às áreas de alto potencial natural. Sob essa análise, o mapeamento confirmou a coerência da distribuição espacial do gradiente fragilidade ambiental produzido nesta pesquisa em função das intervenções antrópicas observadas na paisagem.

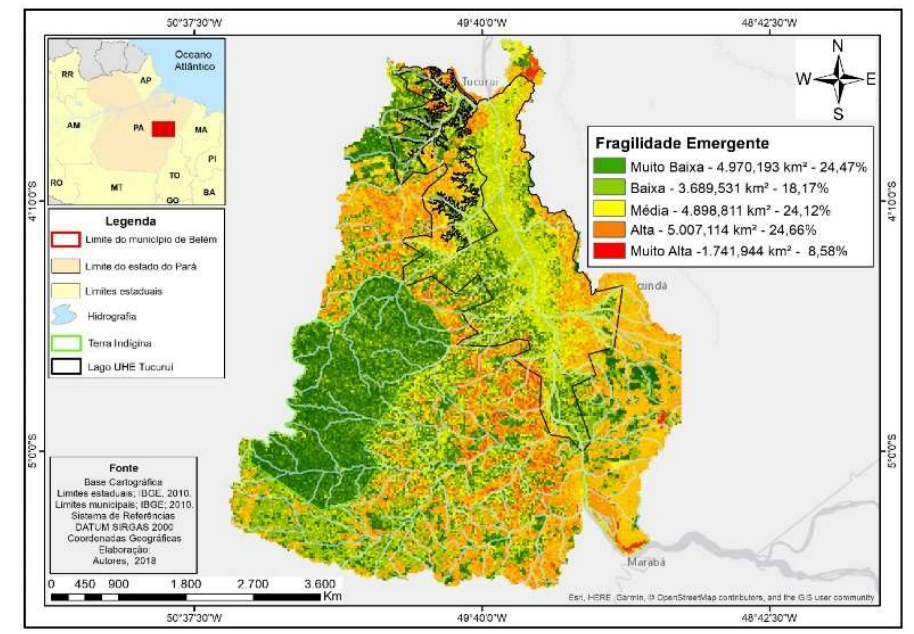

Figura 3: Mapas de Fragilidade Ambiental Emergente na bacia hidrográfica.

O mapa de fragilidade emergente permite dizer que a cobertura florestal é capaz de oferecer proteção ao solo, minimizar a intensidade e as consequências dos processos erosivos e, consequentemente, reduzir a fragilidade em determinados locais os quais, pela Fragilidade Potencial, seriam considerados de alta fragilidade. Em ambos os modelos gerados (Fragilidade emergente e potencial), os graus de fragilidade baixa e média predominaram em áreas caracterizadas por muito baixa declividade e pela ocorrência de Latossolos e argissolos, localizadas em parte dos setores nordeste e sudeste da bacia.

O modelo apresentado para fragilidade emergente, com o objetivo de subsidiar o planejamento de uso na Bacia do Submédio Tocantins, indicou áreas de fragilidade muito alta em locais de áreas urbanas com infraestrutura precária e nos terços superiores de morros e passagens rochosas. Tais áreas são consideradas como prioritárias para a preservação das funções ecossistêmicas.

\section{CONSIDERAÇÕES FINAIS}

O mapa de fragilidade ambiental tem por objetivo a espacialização do comportamento do meio natural e analisar as respostas do meio às intervenções antrópicas. Essa representação tem como produto um conjunto de interpretações dos diferentes planos de informação das condições ambientais relacionadas aos fatores limitantes ao uso e ocupação das terras, processo útil ao planejamento territorial e de réplica relativamente acessível, devido à disponibilidade dos dados oficiais e às técnicas de análise. Os fatores avaliados na análise são capazes de exercer grande influência no desenvolvimento de processos sociais e 
ecológicos. O produto dessas interações complexas pode contribuir para o equilíbrio ambiental, trazendo benefícios econômicos e ecológicos.

As atividades antrópicas, se realizadas sem os devidos estudos técnico-científicos, de forma clara, transparente e participativa, podem levar à perda de qualidade ambiental e comprometer o aproveitamento econômico dos recursos naturais, como o ecoturismo e o valor econômico agregado ao patrimônio genético. O Mapa de Fragilidade Emergente destaca o papel da cobertura florestal para a estabilidade no ambiente, reduzindo a área de fragilidade muito alta. Dessa forma, foram identificadas áreas prioritárias para a preservação e conservação ambiental, servindo assim, de instrumento importante para o planejamento territorial em bacias hidrográficas.

O método empregado é promissor como subsídio à tomada de decisões no que tange a intervenções na paisagem, gestão ambiental e planejamento territorial, como para a elaboração de programas de preservação de áreas florestais. A identificação de áreas de risco, considerando-se a vulnerabilidade natural do ambiente, juntamente com as validações das classificações da terra são essenciais para o monitoramento e a elaboração de Planos Diretores e de Manejo e para projetos conservacionistas.

Os produtos cartográficos finais foram capazes de traduzir a realidade ambiental de maneira simples e de fácil compreensão, além de serem passíveis de atualização em função da base de dados de entrada nos modelos como, por exemplo, mapas de uso e cobertura mais recentes. $\mathrm{O}$ aprimoramento dessas ferramentas possibilita um diagnóstico cada vez mais eficiente da fragilidade dos ambientes, através do zoneamento das áreas de expansão urbana e recuperação/preservação de áreas prioritárias.

\section{REFERÊNCIAS}

ALVES, C. S. L.. Avaliação sazonal e temporal de variáveis físico-químicas no reservatório de Tucuruí-Pa. Dissertação (Mestrado em Geologia e Geoquímica) - Universidade Federal do Pará, Belém, 2005.

ANA. Agência Nacional de Águas. Estado das Águas no Brasil 2002: em busca do equilíbrio. Brasília: ANA, 2002.

ANEEL. Agência Nacional de Energia Elétrica. Atlas Hidrológico do Brasil. Brasília: ANEEL, 1999.

ARAÚJO, R.; GOEDERT, W. J.; LACERDA, M. P. C.. Qualidade de um solo sob diferentes usos e sob cerrado nativo. Revista Brasileira de Ciências do Solo, Viçosa, v.31, n.5, p.10991108, 2007.

CREPANI, E.; MEDEIROS, J. S.; AZEVEDO, L. G.; DUARTE, V.; HERNANDEZ, P.; FLORENZANO, T.. Sensoriamento remoto e geoprocessamento aplicados ao zoneamento ecológicoeconômico e ao ordenamento territorial. São José dos Campos: INPE, 2001.

ELETROBRAS. Centrais Elétricas Brasileiras. Plano Diretor de Meio Ambiente do Setor Elétrico 1991/93. Rio de Janeiro: ELETROBRAS, 1990.

EMBRAPA. Empresa Brasileira de Pesquisa Agropecuária. Sistema brasileiro de classificação de solos. Rio de Janeiro: EMBRAPA, 2006.
ESPÍNDOLA, E. L. G.; MATSUMURA-TUNDISI, T.; RIETZLER, A. C.; TUNDISI, J. G.. Spatial heterogeneity of the Tucuruí reservoir (state of Pará, Amazônia, Brazil) and the distibution of zooplanktonic species. Revista Brasileira de Biologia, v.60, n.2, p.179-194, 2000.

FGV. Fundação Getúlio Vargas. Plano Nacional de Recursos Hídricos: Bacia do Tocantins. Brasília: FGV, 1998.

GRIGIO, A. M.. Aplicação de sensoriamento remoto e sistema de informação geográfica na determinação da vulnerabilidade natural e ambiental do município de Guamaré (RN): simulação de risco às atividades da indústria petrolífera. Dissertação (Mestrado) - Universidade Federal do Rio Grande do Norte, Natal, 2003.

JAIN, S. K.; GOEL, M. K.. Assessing the vulnerability to soil erosion of the Ukai Dam catchments using remote sensing and GIS. Hydrological Sciences Journal, v.47, p.31-40, 2002. DOI: http://doi.org/10.1080/02626660209492905

KAWAKUBO, F. S.; MORATO, R. G.; ROSS, J. L. S.. Caracterização empírica da fragilidade ambiental utilizando geoprocessamento. In: SIMPÓSIO BRASILEIRO DE SENSORIAMENTO REMOTO, 12. Anais. São José dos Campos: INPE, 2005. 
LEME, S. M.. processos geoecológicos e sócio/ reprodutores e a fragilidade ambiental da bacia do ribeirão. Tese

(Doutorado) - Universidade de São Paulo, Piracicaba, 2007.

LIMA, C. J. S.. Efeitos da fragmentação e isolamento da paisagem na riqueza e composição de espécies de lagartos no reservatório de Tucuruí, Pará. Dissertação (Mestrado em Ciências Ambientais) - Universidade Federal do Pará, Belém, 2005.

RODRIGUES, J. B. T.; ZIMBACK, C. R. L.; PIROLI, E. L. Utilização de Sistema de Informação Geográfica na Avaliação do Uso da Terra em Botucatu (SP). Revista Brasileira de Ciência do Solo, v.3, n.25, p.675-681, 2001. DOI: http://doi.org/10.1590/S0100-06832001000300016
ROSS, J. L. S.. Análise empírica da fragilidade dos ambientes naturais e antrópizados. Revista Departamento de Geografia, São Paulo, n.8, 1994.

ROSS, J. L. S.. Landforms and environmental planning: Potentialities and Fragilities. Revista do Departamento de Geografia, São Paulo, p.38-51, 2012.

SPÖL, C.. Análise da fragilidade ambiental relevo-solo com aplicação de três modelos alternativos nas altas bacias do rio Jaguarim- Mirim, Ribeirão do Quartel e Ribeirão da Prata. Dissertação (Mestrado em Geografia Física) Universidade de São Paulo, São Paulo, 2001.

VALLE, I. C.; FRANCELINO, M. R.; PINHEIRO, H. S. K.. Mapeamento da Fragilidade Ambiental na Bacia do Rio Aldeia Velha, RJ. Floresta e Ambiente, v.23, n.2, p.295-308, 2016.

A CBPC - Companhia Brasileira de Produção Científica (CNPJ: 11.221.422/0001-03) detém os direitos materiais desta publicação. Os direitos referem-se à publicação do trabalho em qualquer parte do mundo, incluindo os direitos às renovações, expansões e disseminações da contribuição, bem como outros direitos subsidiários. Todos os trabalhos publicados eletronicamente poderão posteriormente ser publicados em coletâneas impressas sob coordenação da Sustenere Publishing, da Companhia Brasileira de Produção Científica e seus parceiros autorizados. Os (as) autores (as) preservam os direitos autorais, mas não têm permissão para a publicação da contribuição em outro meio, impresso ou digital, em português ou em tradução. 